Research Article

\title{
Research on RMB Exchange Rate Volatility Risk Based on MSGARCH-VaR Model
}

\author{
Xiaofei Wu (D), Shuzhen Zhu (D), and Junjie Zhou (D) \\ Glorious Sun School of Business and Management, Donghua University, Shanghai 200051, China \\ Correspondence should be addressed to Shuzhen Zhu; z_shuzhen@dhu.edu.cn
}

Received 4 April 2020; Accepted 1 July 2020; Published 1 August 2020

Guest Editor: Lin-Yun He

Copyright (c) 2020 Xiaofei Wu et al. This is an open access article distributed under the Creative Commons Attribution License, which permits unrestricted use, distribution, and reproduction in any medium, provided the original work is properly cited.

\begin{abstract}
This paper captures the RMB exchange rate volatility using the Markov-switching GARCH (MSGARCH) models and traditional single-regime GARCH models. Through the Markov Chain Monte Carlo (MCMC) method, the model parameters are estimated to study the volatility dynamics of the RMB exchange rate. Furthermore, we compare the MSGARCH models to the single-regime GARCH specifications in terms of Value-at-Risk (VaR) prediction accuracy. According to the Deviance information criterion method, the research shows that MSGARCH models outperform the single-regime specifications in capturing the complexity of RMB exchange rate volatility. After the RMB exchange rate reform in 2015, the volatility is more asymmetric and persistent, and the probability of being in the turbulent volatility regime is significantly increased. The continuous escalation of Sino-US trade friction has increased the $\mathrm{VaR}$ of $\mathrm{RMB}$ exchange rate log-returns. From the evaluation results of the actual over expected exceedance ratio (AE), the conditional coverage (CC) test, and the dynamic quantile (DQ) test, we find strong evidence that tworegime MSGARCH models could forecast VaR more accurately, which provides practical value for China's foreign exchange management authorities to manage the financial risk.
\end{abstract}

\section{Introduction}

$\mathrm{RMB}$ is the national currency of the largest exporter and the second largest importer in the world. As the price of currency exchange between two countries, RMB exchange rates are particularly important for the stability of economic and trade cooperation between China and other countries. Exchange rate volatility has gradually the attention of market traders. On July 21, 2005, the People's Bank of China (PBOC) implemented the second major reform of the RMB exchange rate formation mechanism. Concerning a basket of currencies for adjustment and management, PBOC decided not to peg solely to the US dollar but to implement the floating exchange rate system based on market supply and demand. Before July 2005, although the exchange rate system in China had always been a managed floating exchange rate system, its essence was to adopt a fixed exchange rate system in which the RMB is fixed on the dollar. The exchange rate between the US dollar and the RMB will remain within the range of $8.27-8.30$ until July 2005 . In June
2008, to cope with the impact of the global financial crisis, the $\mathrm{RMB}$ exchange rate was pegged to the US dollar again until June 2010, when it returned to the RMB exchange rate system pegged to a basket of currencies. Since then, the central parity of the RMB exchange rate has been given a more market-oriented form. Meanwhile, the volatility of the $\mathrm{RMB}$ exchange rates has also intensified and presented multiple complexities.

On August 11, 2015, PBOC implemented the third major reform of the RMB exchange rate system, announcing the adjustment of the quotation mechanism for the central parity rate of RMB against the US dollar. Market makers could refer to the closing price of the foreign exchange market on the previous day before opening and report the intermediate price to China's foreign exchange trading center. The RMB exchange rates have been further commercialized and the flexibility of two-way floating has been significantly increased. On the day of the exchange rate reform in 2015, the closing price of the exchange rate versus the US dollar plunged 1136 basis points compared with the 
previous opening day. This turmoil has released market signals of increased exchange rate volatility. On May 26, 2017, China's central bank announced the addition of countercyclical factors to the RMB exchange rate formation mechanism, to weaken the herding effect in the foreign exchange market and slow down the sharp volatility of the RMB exchange rate. On August 5, 2019, influenced by the unilateralism and trade protectionism measures of the United States and the expectation of imposing a tariff on China, the onshore and offshore RMB exchange rates versus the US dollar both exceeded the " 7 ," reaching a new low in 11 years. In this context, for foreign-related enterprises and commercial banks in China, the management of RMB exchange rate risk is particularly important. Further, the key point is to accurately grasp the fluctuation mode of the RMB exchange rate under the new exchange rate system. Additionally, the issue that how to accurately measure the RMB exchange rate risk will become the top priority of risk managers.

Based on the consideration above, this paper considers Markov-switching GARCH (MSGARCH) models to capture the structural changes of the RMB exchange rate volatility through Markov Chain Monte Carlo (MCMC) parameter estimation method. We also discuss the model estimation effect of the MSGARCH models and traditional single-regime GARCH models. Furthermore, the MSGARCH model is combined with the Value-at-Risk (VaR) method to evaluate the accuracy of MSGARCH models and traditional single-regime GARCH specifications in terms of risk prediction. The empirical results have great theoretical significance for the risk prediction and risk management of the $\mathrm{RMB}$ exchange rate.

The structure of the paper is as follows: Section 2 is a review of the related literature. The selected model specifications and related methodology are provided in Section 3. We describe the data and variables used in this article and apply the model specifications to study the volatility dynamics of the RMB exchange rates in Section 4. Finally, the main conclusions are in Section 5.

\section{Literature Review}

The characteristics of exchange rate volatility have always been a hot topic for scholars, gradually showing new characteristics with different financial and economic environments. Based on the empirical analysis of linear and nonlinear GARCH models, foreign scholars have obtained four nonlinear characteristics: thick tail and clustering, asymmetry, and negative correlation [1-3]. Thick tail and clustering refer to the high probability and clustering of extreme values in financial time series. Domestic scholars have done a lot of research on this characteristic. Pan [4] used the GARCH model and EGARCH model to study the operating characteristics of the RMB exchange rate before and after the exchange rate reform in 2015. The results showed that, after the exchange rate reform, the RMB exchange rate had been in a high volatility regime for a long time, and the linkage between the RMB exchange rate on the onshore and offshore markets had been strengthened.
Through empirical research, He [5] obtained that RMB internationalization increased the volatility range and continuity of exchange rate, and $\mathrm{RMB}$ exchange rate volatility changed from one-way appreciation volatility to twoway volatility. Sun and Sun [6] used ARIMA-GARCH empirical model to conclude that RMB's exchange rate volatility had persistence and leverage effect after the entry of RMB into SDR.

Asymmetry and negative correlation mean that the probability of negative return extreme value is greater and it is more prone to high volatility. Hamilton [7] was the first to introduce Markov regime-switching model into financial time series analysis. After that, it is widely used in financial asset time series analysis. The model could divide the volatility of the time series into several different regimes to analyze the volatility characteristics in different regimes [8-10]. Zhang et al. [11] used different types of Markov regime-switching GARCH models to estimate the volatility for the daily and weekly crude oil prices. The results showed that the regime-switching GARCH models help to identify the structural changes in volatility, which displayed the superiority compared to the single-regime GARCH models. Furthermore, Zhang et al. found that the MSGARCH model did not perform better than the single-regime GARCH specifications when predicting the VaR. At present, many domestic scholars have applied the MSGARCH model to Chinese financial market research. Based on the improved Student- $t$ conditional distribution, Wei [12] studied that Markov regime-switching GARCH models were better than single-regime GARCH models in fitting degree and prediction effect for stock market data. Yang et al. [13] selected the Shanghai Composite Index and Shenzhen Composite Index to study the effects of parametric MSGARCH model and nonparametric MSGARCH model on $\mathrm{VaR}$ forecasts. The results showed that the nonparametric model performed better in terms of the effect of VaR forecasts. Ji [14] used a variety of Markov regime-switching GARCH models to measure the uncertainty of the GDP growth rate. The study found that MSGARCH models could analyze the sources of uncertainty more accurately. Huang et al. [15] used a dynamic multidimensional conditional correction MSGARCH model to study the prediction effect of exchange rate volatilities. The results showed that MSGARCH models with three regimes had a better prediction effect of exchange rate volatilities.

Generally, there is a lot of literature studies on the MSGARCH models, while there are few works of literature on the advantages and disadvantages of the regimeswitching MSGARCH model and the single-regime GARCH model in risk loss prediction. As for the parameter estimation method, the Maximum Likelihood Estimation (MLE) method is selected by most scholars to estimate the parameters of the MSGARCH model [16]. However, the MLE method is difficult to accurately estimate the model parameters [17]. Markov Chain Monte Carlo (MCMC) method is used to estimate the parameters of the MSGARCH models. MCMC method can estimate the model parameters 
of posterior distribution more accurately, solving the local maximum convergence of the MLE method. Firstly, tworegime MSGARCH models with the single-regime counterparts were compared and estimated different kinds of regime-switching MSGARCH models estimated by the MCMC method. Then, we select the MSGARCH model with the best fitting effect to study the dynamic volatility of the RMB exchange rates. In terms of research content, the volatility characteristics of the RMB exchange rate are worth studying under the new exchange rate system after the exchange rate reform in 2015. Further, considering the VaR (Value-at-Risk) measurement method, this paper discusses the accuracy of MSGARCH specifications and the traditional GARCH specifications in terms of the risk measurement of the RMB exchange rate. In addition, improving the empirical model to study RMB exchange rate volatility aims at providing an effective measurement for risk managers of financial institutions in China.

\section{Methodology}

3.1. MSGARCH Model. Engle was the first to propose the autoregressive conditional heteroscedasticity (ARCH) model, which solved the problems caused by heteroscedasticity. Bollerslev extended the ARCH model and proposed a generalized autoregressive conditional heteroscedasticity $(\mathrm{GARCH})$ model to solve the problem of the too-long lag period in the ARCH model. Since then, GARCH model functions have been widely studied and extended by scholars. Nelson proposed the EGARCH model of a univariate index, which overcomes the problem that the estimated parameters must be nonnegative. Glosten et al. introduced the leverage effect of negative shocks and proposed the GJR-GARCH model to study the asymmetry of financial time series.

Financial asset returns have the characteristics of sharp peaks and thick tails, and their price volatilities will show asymmetric effects and variability. Based on the Markov regimeswitching GARCH model specified by Gray [18], this paper focuses on the volatility of the RMB exchange rate before and after the "811" exchange rate reform in 2015. The standard Normal distribution, Student- $t$ distribution, and skewed Student- $t$ distribution are, respectively, used to fit in each regime.

Let $y_{\mathrm{t}}$ be the daily exchange rate log-return at time $t$. We assume that $y_{t}$ is serially uncorrelated; that is, the following moment conditions assume that $E\left[y_{t}\right]=0$ and $E\left[y_{t} y_{t-l}\right]=0$ for $l \neq 0$ and all $t>0$. Following Ardia et al., the general form of MSGARCH model can be expressed as

$$
y_{t} \mid\left(s_{t}=k, \Phi_{t-1}\right) \sim D\left(0, h_{k, t}, \xi_{k}\right),
$$

where $D\left(0, h_{k, t}, \xi_{k}\right)$ is the continuous distribution of zero mean, time-varying variance $h_{k, t}$, and additional shape parameters collected in a vector $\xi_{k}$. $\Phi_{t-1}$ represents the information set observed up to time $t-1$, which is $\Phi_{t-1}$ $\equiv\left\{y_{t-i}, i>0\right\}$. Additionally, integer random variable $s_{t}$, defined in discrete space $\{1, \ldots, K\}$, characterizes the Markov regime-switching GARCH models. Standardized innovation is defined as $\eta_{k, t} \equiv y_{t} / h_{k, t}^{1 / 2} \sim \operatorname{iidD}\left(0,1, \xi_{k}\right)$.
It is assumed that $s_{t}$ evolves according to an unobserved first-order ergodic homogeneous Markov chain, and its $K \times$ $K$ transition probability matrix $\mathbf{P}$ is

$$
\mathbf{P} \equiv \begin{array}{ccc}
p_{1,1} & \cdots & p_{1, K} \\
\vdots & \ddots & \vdots \\
p_{K, 1} & \cdots & p_{K, K}
\end{array}
$$

where $p_{i, j} \equiv \mathbf{P}\left[s_{t}=j \mid s_{t-1}=i\right]$ is the probability of a transition from the regime $s_{t-1}=i$ to regime $s_{t}=j$.

Evidently, the following constraints hold: $0<p_{i, j}<1$, $\forall i, j \in\{1, \ldots, K\}$, and $\sum_{j=1}^{K} p_{i, j}=1$. Parameterizing $D(\cdot)$, we have $E\left[y_{t}^{2} \mid s_{t}=k, \Phi_{t-1}\right]=h_{k, t}$; that is, $h_{k, t}$ is the variance of $y_{t}$ conditional on the realization of $s_{t}=k$.

Following Haas [19], conditionally on the regime $s_{t}=k$, we specify $h_{k, t} \equiv h\left(y_{t-1}, h_{k, t-1}, \theta_{k}\right)$ as a function of the previous observation $y_{t-1}$, the previous variance $h_{k, t-1}$, and the additional regime-dependent vector of parameters $\theta_{k}$. In practical application, many studies show that the GARCH (1, 1) model is the best method to accurately capture exchange rate volatility. On this basis, this paper uses two Markov regime-switching GARCH models, respectively, and the GARCH $(1,1)$ model is as follows:

$$
h_{k, t} \equiv \alpha_{0, k}+\alpha_{1, k} y_{t-1}^{2}+\beta_{k} h_{k, t-1} \text {. }
$$

For $k=1,2, \ldots, K$, we have the parameter matrix $\theta_{k}=$ $\left(\alpha_{0, k}, \alpha_{1, k}, \beta_{k}\right)^{T}$ with constraints $\alpha_{0, k}>0, \alpha_{1, k}>0, \beta_{k} \geq 0$, and the GJR-GARCH $(1,1)$ model is as follows:

$$
h_{k, t} \equiv \alpha_{0, k}+\left(\alpha_{1, k}+\alpha_{2, k} \prod\left\{y_{t-1}<0\right\}\right) y_{t-1}^{2}+\beta_{k} h_{k, t-1} \text {. }
$$

$k=1,2, \ldots, K$, where $\prod\{\cdot\}$ is the indicator function taking value one if the condition holds, and zero otherwise. We have the parameter matrix $\theta_{k}=\left(\alpha_{0, k}, \alpha_{1, k}, \alpha_{2, k}, \beta_{k}\right)^{T}$ with constraints $\alpha_{0, k}>0, \alpha_{1, k}>0, \alpha_{2, k} \geq 0, \beta_{k} \geq 0, \quad \alpha_{1, k}+$ $\alpha_{2, k} E\left[\eta_{k, t}^{2} \prod\left\{\eta_{k \cdot t}<0\right\}\right]+\beta_{k}<1$, where asymmetric term parameter $\alpha_{2, k}$ controls the magnitude of asymmetry in the conditional volatility responding to the past impact in regime $k$.

3.2. Value-at-Risk Method. VaR (Value-at-Risk) literally refers to the maximum loss faced by financial asset or portfolio within a certain holding period and the confidence level. It can be expressed as

$$
\operatorname{Prob}\left(\Delta p>\mathrm{VaR}_{1-\alpha}\right)=1-\alpha
$$

where $\Delta p, 1-\alpha$ represents the possible loss and the confidence level. Additionally, during the holding period $\Delta t$, the possibility that the maximum loss of a financial asset exceeds $\mathrm{VaR}$ is $1-\alpha$. When we estimate the $\mathrm{VaR}$, three variables need to be determined. The first is the confidence level. Managers can determine a confidence level based on the degree of risk aversion. The Basel Committee on Banking Supervision (BCBS) requires commercial banks to adopt the 99\% confidence level. The second is the holding period of financial assets; that is, managers want to calculate the maximum risk value in one day, one week, or one month. The longer the holding period of the same assets, the greater 
the risk value. BCBS also stipulates that banks should adopt 10 trading days as the holding period. The last is the observation period, that is, the historical data window of an asset. The calculated value needs to be based on certain historical data to determine its volatility characteristics.

In order to compare the dynamic VaR prediction effects of single-regime MSGARCH models and two-regime MSGARCH models, the actual over expected exceedance ratio (AE), the conditional coverage (CC) test by Christoffersen [20], and the dynamic quantile (DQ) test by Engle and Manganelli [21] are used to evaluate the VaR forecasts.

\section{Empirical Results}

4.1. Data Source and Processing. RMB daily exchange rates (USD/CNY, JPY/CNY, and HKD/CNY) are from the State Administration of Foreign Exchange. The time period ranges from June 21, 2010, to December 23, 2019, for a total of 2315 observations (the detailed data is in the Supplementary Materials). The original sample data of the RMB exchange rate is subjected to first-order logarithmic differential processing. Then, the daily log-returns of RMB exchange rates are calculated with the formula

$$
R_{t}=100 * \ln \left(\frac{P_{t}}{P_{t-1}}\right) \text {. }
$$

4.2. Summary Statistics. Table 1 shows the summary statistics of the daily log-returns of RMB exchange rates. According to the descriptive statistics reported in Table 1, the mean of all log-return series is close to 0. RJPY has the largest absolute return rate, while RUSD and RHKD have the same absolute return rate. Additionally, the skewness of RUSD and RHKD is significant, small, and positive, showing that the upper tail of the empirical distribution of the logreturns is longer than the lower tail, while the lower tail of the empirical distribution of the RJPY log-returns is longer. Consequently, it can be significantly seen that the empirical distribution of the RMB exchange rate log-returns is asymmetric. The kurtosis is far higher than the normal value of 3 for all log-return series. The significant values of JarqueBera show that all log-return series reject the null hypothesis of normally distributed errors. The significant values of ADF (Augmented Dickey-Fuller test) indicate that all the logreturn series are stationary under the $1 \%$ confidence level. Further, the ARCH-LM values of all the log-return series are significant under the $1 \%$ confidence level, rejecting the null hypothesis of no ARCH effect. Therefore, this paper uses GARCH models to capture the volatility of RMB exchange rates log-return series.

4.3. Comparison of MSGARCH Models Based on MCMC Method. Based on the Markov Chain Monte Carlo (MCMC) method, we consider GARCH $(1,1)$ model and GJR-GARCH $(1,1)$ model up to two regimes, using the Normal distribution, the (Standardized) Student- $t$ distribution, and the skewed (Standardized) Student- $t$ distribution, to fit the 12 models of each RMB exchange rate to the
TABLE 1: Summary statistics of RMB exchange rate log-returns.

\begin{tabular}{lccc}
\hline Statistic & RUSD & RJPY & RHKD \\
\hline Mean & -0.001150 & -0.007121 & 0.001001 \\
Maximum & 1.840324 & 3.627312 & 1.841136 \\
Minimum & -1.065088 & -5.149659 & -1.131160 \\
Standard deviation & 0.169035 & 0.555590 & 0.167636 \\
Kurtosis & 17.49784 & 10.19034 & 17.34420 \\
Skewness & 0.983511 & -0.365176 & 0.982192 \\
Jarque-Bera & $20638.60^{* *}$ & $5036.266^{* *}$ & $20210.37^{* *}$ \\
ADF & $-43.72090^{* *}$ & $-46.32599^{* *}$ & $-44.21325^{* *}$ \\
ARCH-LM & $417.1975^{* *}$ & $12.04013^{* *}$ & $400.9284^{* *}$ \\
\hline
\end{tabular}

Note. ${ }^{*},{ }^{* *}$ means rejection of the null hypothesis at the $5 \%$ and $1 \%$ level, respectively.

full history of data. In total 30,000 MCMC draws, we use 5,000 burn-in draws and the next 25,000 draws keeping only every 5th draw to eliminate the autocorrelation, thus a posterior sample of size 5,000. In order to evaluate the goodness-of-fit of the different MSGARCH models, we use the Deviance information criterion (DIC) by Spiegelhalter et al. [22] in the Bayesian estimation method.

Table 2 shows the DIC of 36 MSGARCH models overall. According to the Deviance information criterion that the smaller the DIC value is, the better the model fitting is, for all volatility and distribution specifications, the DIC value of two-regime MSGARCH models is smaller than single-regime counterparts. Therefore, the two-regime MSGARCH models are better than the single-regime counterparts in fitting quality and model complexity. Further, it can be noticed that, for all regime specifications, the model fitting results under the Student- $t$ conditional distribution and the skewed Student- $t$ conditional distribution are better than the corresponding model fitting results under the Normal conditional distribution. Thus, the log-return series of the RMB exchange rate has the characteristics of sharp-peak, fattail, and asymmetric distribution.

4.4. Analysis of the Volatility of RMB Exchange Rate. In this case, the two-regime GJR-MSGARCH $(1,1)$-t model is used to analyze regime changes in the volatility dynamics of three kinds of RMB exchange rate based on the MCMC method. Table 3 shows the mean and standard deviation (SD) of the posterior distribution for the model parameters.

According to the estimation results of model parameters of RUSD/CNY, the mean value of GARCH coefficient in regime one $\beta_{1}$ is 0.2026 , which is smaller than the mean value of ARCH coefficient $\alpha_{1,1}(0.4366)$. This sign significantly indicates that RUSD/CNY exchange rate in regime one has weak agglomeration effect and memory, while the external impact has a strong influence on RMB exchange rate volatility. The mean value of ARCH coefficient $\alpha_{1,2}$ and GARCH coefficient $\beta_{2}$ of the model in regime two is 0.2122 and 0.6975 , respectively, which shows that the RUSD/CNY exchange rate in regime 2 has a strong agglomeration effect and memory. The volatility of the previous period has an impact on the volatility of the next period, while the impact of external shocks on the volatility of the exchange rate is relatively weak. $\alpha_{1,1}+0.5 \alpha_{2,1}+\beta_{1} \approx 0.6424$ in regime one 
TABLE 2: DIC results of different MSGARCH models.

\begin{tabular}{lccc}
\hline & RUSD & RJPY & RHKD \\
\hline Single regime & & & \\
GARCH-N & -2362.29 & 3666.25 & -2362.95 \\
GARCH-t & -3269.09 & 3335.50 & -3236.02 \\
GARCH-SKT & -3298.95 & 3336.26 & -3255.59 \\
GJR-GARCH-N & -2361.38 & 3670.49 & -2360.96 \\
GJR-GARCH-t & -3287.85 & 3337.97 & -3236.86 \\
GJR-GARCH-SKT & -3285.44 & 3342.61 & -3253.50 \\
\hline Two regimes & & & \\
GARCH-N & -3245.84 & 3373.09 & -3016.40 \\
GARCH-t & -3378.92 & 3332.42 & -3364.52 \\
GARCH-SKT & -3361.55 & 3327.7 & -3352.81 \\
GJR-GARCH-N & -3283.83 & 3380.58 & -3198.67 \\
GJR-GARCH-t & -3325.49 & 3335.59 & -3325.84 \\
GJR-GARCH-SKT & -3335.64 & 3351.08 & -3352.69 \\
\hline
\end{tabular}

Note. $N, S$, and SKT represent the Normal distribution, Student- $t$ distribution, and skewed Student- $t$ distribution, respectively.

TABle 3: Parameter estimates of the GJR-MSGARCH $(1,1)-\mathrm{t}$ model.

\begin{tabular}{lcccccc}
\hline & \multicolumn{2}{c}{ RUSD } & \multicolumn{2}{c}{ RJPY } & \multicolumn{2}{c}{ RHKD } \\
& Mean & SD & Mean & SD & Mean & SD \\
\hline$\alpha_{0,1}$ & 0.0040 & 0.0023 & 0.0702 & 0.0913 & 0.0044 & 0.0019 \\
$\alpha_{1,1}$ & 0.4366 & 0.2044 & 0.1204 & 0.1203 & 0.3226 & 0.1373 \\
$\alpha_{2,1}$ & 0.0063 & 0.0110 & 0.1856 & 0.2403 & 0.0046 & 0.0081 \\
$\beta_{1}$ & 0.2026 & 0.3506 & 0.4516 & 0.4157 & 0.1516 & 0.2839 \\
$\nu_{1}$ & 6.0082 & 5.0719 & 7.4159 & 3.4021 & 5.7605 & 5.0877 \\
$\alpha_{0,2}$ & 0.0013 & 0.0024 & 0.1579 & 0.2007 & 0.0007 & 0.0018 \\
$\alpha_{1,2}$ & 0.2122 & 0.2156 & 0.0842 & 0.0816 & 0.1363 & 0.1239 \\
$\alpha_{2,2}$ & 0.0181 & 0.0112 & 0.0604 & 0.1312 & 0.0186 & 0.0083 \\
$\beta_{2}$ & 0.6975 & 0.3550 & 0.5876 & 0.4236 & 0.7847 & 0.2881 \\
$\nu_{2}$ & 11.2659 & 5.5452 & 7.1575 & 3.9709 & 14.7782 & 6.6129 \\
$p_{1,1}$ & 0.9786 & 0.0048 & 0.9413 & 0.0369 & 0.9767 & 0.0048 \\
$p_{2,1}$ & 0.0168 & 0.0055 & 0.0504 & 0.0512 & 0.0155 & 0.0058 \\
\hline
\end{tabular}

and $\alpha_{1,2}+0.5 \alpha_{2,2}+\beta_{2} \approx 0.9188$ in regime two. Indeed, it is noticed that the unconditional annualized volatility in regime one is $1.636 \%$, while the unconditional annualized volatility in regime two is $2.352 \%$. In summary, the RUSD/ CNY exchange rate has regime changes in volatility dynamics. Further, the regime one corresponds to the stable condition of the exchange rate volatility, and regime two corresponds to the turbulent condition of the exchange rate volatility. The mean values of the asymmetric coefficients $\alpha_{2,1}, \alpha_{2,2}$ are 0.0063 and 0.0181 , respectively, showing stronger asymmetric effect in regime two, namely, the turbulent condition of the exchange rate volatility. The mean values of the parameters $p_{1,1}$ and $p_{2,1}$ are 0.9786 and 0.0168 , which, respectively, represent the probability of RUSD/CNY exchange rate volatility moving from regime one to regime one and from regime two to regime one. The values of $p_{1,2}$ and $p_{2,2}$ are 0.0214 and 0.9832 , respectively, indicating that the RUSD/CNY exchange rate is more likely to be in the same regime and the probability of transition between two regimes is very small. According to the sample proportions in different regimes, the exchange rate in a stable volatility regime is $43.9 \%$, and in turbulent volatility, the regime is
56.1\%. Thus RUSD/CNY exchange rate fluctuates turbulently for a long time and stably for a short time.

The unconditional annualized volatility of the RJPY/ CNY exchange rate is $7.554 \%$ and $11.499 \%$, respectively, for regime one and regime two, indicating that regime one is a stable condition of the exchange rate volatility and regime two is a turbulent condition of the exchange rate volatility. During the sample period, the rates of RJPY/CNY exchange rate in regime one and in regime two were $46.2 \%$ and $53.8 \%$, respectively, showing that the exchange rate volatility has been in a regime of turbulent condition for a longer period of time after June 2010. According to the estimated results of model parameters, it can be seen that RJPY/CNY exchange rate volatility has a stronger long memory and clustering effect when the exchange rate fluctuates turbulently in regime two. Additionally, RJPY/CNY exchange rate volatility is more vulnerable to the influence of previous volatility, and the exchange rate shows a strong asymmetric effect in both regimes. The probability of regime transitions $p_{1,1}$ and $p_{2,1}$ is 0.9413 and 0.0504 , respectively, indicating that RJPY/CNY exchange rate volatility is more likely to be in the same regime and is less likely to switch between different regimes.

According to the model parameters estimation of $\mathrm{RHKD} / \mathrm{CNY}$ exchange rate, in regime two, the mean value of GARCH coefficient $\beta_{2}$ is larger than the mean value of ARCH coefficient $\alpha_{1,2}$. Then, we can find that the RHKD/ $\mathrm{CNY}$ exchange rate volatility in regime two is more susceptible to the influence of the previous volatility and has a strong memory. In regime one, the mean value of GARCH coefficient $\beta_{1}$ is smaller than the mean value of $\mathrm{ARCH}$ coefficient $\alpha_{1,1}$, indicating that $\mathrm{RHKD} / \mathrm{CNY}$ exchange rate volatility in regime one has the weaker aggregation effect and memory. The first regime reports $\alpha_{1,1}+0.5 \alpha_{2,1}+\beta_{1} \approx 0.4765$, while the second regime reports $\alpha_{1,2}+0.5 \alpha_{2,2}+\beta_{2} \approx 0.9303$. Additionally, the two regimes report the different unconditional annualized volatility of the exchange rate: $39.93 \%$ and $60.07 \%$. The mean value of the asymmetric terms' coefficient is 0.0046 and 0.0186 , respectively. In summary, it can be seen that RHKD/CNY exchange rate volatility shows a more obvious asymmetric effect under the turbulent condition (regime two). The values of the parameters $p_{1,1}$ and $p_{2,2}$ are 0.9767 and 0.9845 , respectively, indicating that $\mathrm{RHKD} / \mathrm{CNY}$ exchange rate volatility is also more likely to be in the same regime and has a lower probability of regime transition. According to the sample proportions in different regimes, the exchange rate in a stable volatility regime is $39.93 \%$, and in turbulent volatility, the regime is $60.07 \%$. Therefore, the RUSD/CNY exchange rate fluctuated turbulently for a longer period of time in the sample period, while the time in the stable volatility regime was shorter.

USD/CNY exchange rate has always been the most concerned exchange rate index of PBOC and market traders. Then, we focus on the analysis of the volatility dynamics of the RUSD/CNY exchange rate since June 2010. Figure 1 shows the conditional volatility (annualized) of the RUSD/ CNY exchange rate based on the GJR-MSGARCH-t model.

Figure 1 displays that, during the whole sample period from June 2010 to December 2019, the RUSD/CNY 


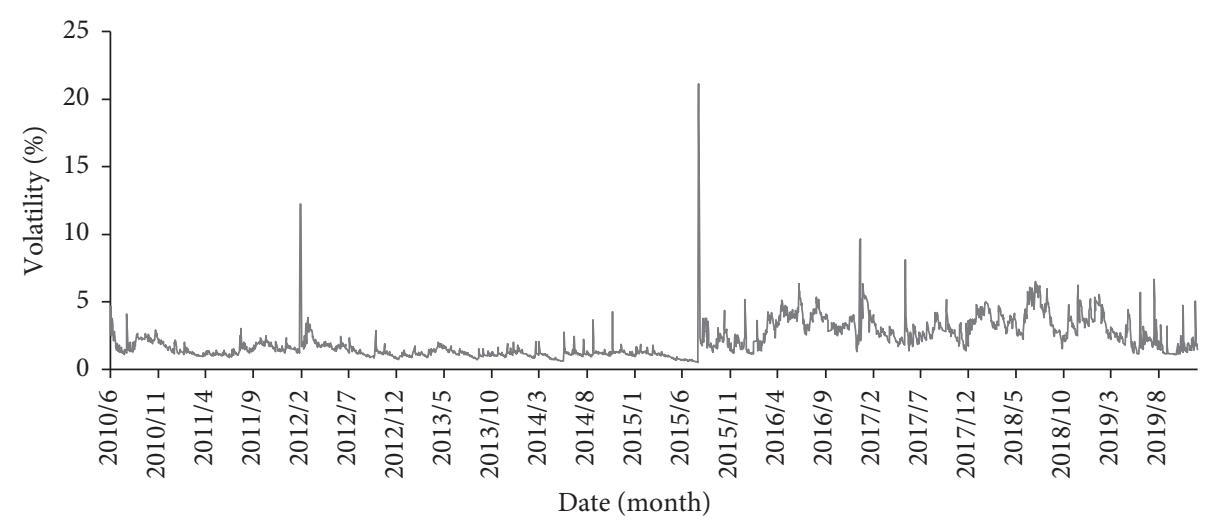

FIgURE 1: Annualized conditional volatility of the RMB-US dollar exchange rate.

exchange rate fluctuated turbulently for a longer period of time. This is mainly because $\mathrm{PBOC}$ changed from pegging to the dollar exchange rate to a basket of currency exchange rates after the end of the international financial crisis in 2010. In addition, the " 811 " exchange rate reform in 2015 and the entry of RMB into SDR in 2016 further increased the volatility range of the exchange rate market while improving the marketization of RMB. At the same time, the trade friction between China and the United States also increased the uncertainty of the exchange rate market. Before the exchange rate reform in 2015, RUSD/CNY exchange rate fluctuated in a low-frequency mode for a longer period of time, with the annual volatility rate basically below $5 \%$, while the exchange rate fluctuated in a higher frequency after the exchange rate reform. In particular, the entry of RMB into SDR objectively requires further marketization of the RMB exchange rate, which also increases the fluctuation of the RMB exchange rate market. As is illustrated in Figure 1, the annualized conditional volatility of the RMB exchange rate in 2017 exceeds $8 \%$ twice. The trade disputes between China and the United States in April 2018 further intensified the volatility of the RMB exchange rate. It can be seen that the annual volatility of the exchange rate has frequently exceeded $5 \%$ since then.

Figures 2 and 3 display the estimated smoothed probabilities of both regimes for the GJR-MSGARCH-t model (RUSD/CNY). Before the exchange rate reform in 2015, the smoothed probabilities of the second regime (the turbulent condition) seldom exceed 0.5. Since then, the smoothed probabilities of the second regime has increased significantly. It can be seen that, before the exchange rate reform in 2015, the exchange rate versus the US dollar was relatively stable with obvious long-term memory. It is due to the low degree of marketization of the RMB exchange rate and the strict exchange rate control by the State Administration of Foreign Exchange. After the exchange rate reform in 2015, the exchange rate versus the US dollar has entered a stage with a high probability of violent volatility. Figures 1-3 depict that, after the exchange rate reform in 2015, the annualized conditional volatility of the exchange rate versus the US dollar has increased significantly, and the probability of the second regime (the turbulent condition) has increased significantly as well. During the period from August 2015 to
March 2016, external shocks had a greater impact on the volatility of the RMB exchange rate, showing that the degree of marketization of the RMB exchange rate has improved after the exchange rate reform. After March 2016, the volatility of the RMB exchange rate has entered a relatively stable stage again. During the period from April 2018 to December 2019, the exchange rate versus the US dollar fluctuated frequently and violently (see Figure 1). The probability of the volatility of the exchange rate in turbulent conditions was at a high level (see Figure 3), reflecting that the uncertainty of the trade disputes between China and the United States had a significant impact on the RMB exchange rate.

4.5. Dynamic VaR Prediction of Different MSGARCH Models. Markov-switching two-regime GARCH models have a better fitting effect in capturing RMB exchange rate volatility, but their effect on risk management and prediction needs further testing. In order to compare the prediction results of the single-regime MSGARCH models and the tworegime MSGARCH models, the actual over expected exceedance ratio (AE), the conditional coverage (CC) test, and the dynamic quantile (DQ) test are used to evaluate the daily VaR prediction performance. Based on the Student- $t$ conditional distribution, the last 500 data (December 4, 2017, to December 23, 2019) are for out-of-sample observations, and $800 \log$-returns of the RMB exchange rate are used for the rolling-window estimation. The model parameters are updated every 10th observation, so as to improve the prediction accuracy of the model.

Table 4 shows the one-day ahead VaR results of three kinds of RMB exchange rates at a $1 \%$ risk level. According to $\mathrm{AE}$ criteria, if the value of $\mathrm{AE}$ is closed to 1, the analyzed model has better prediction accuracy. From the results of the $\mathrm{AE}$ values, CC back-testing, and DQ back-testing, for all kinds of RMB exchange rate log-return series, the two-regime MSGARCH models forecast the VaR more accurately at $1 \%$ risk level than the single-regime counterparts. Further, for all model specifications, GJR-GARCH-t models are more suitable for the one-day ahead VaR prediction.

Figure 4 displays the one-day ahead $\mathrm{VaR}$ forecasts at the $1 \%$ risk level based on the single-regime MSGARCH models 


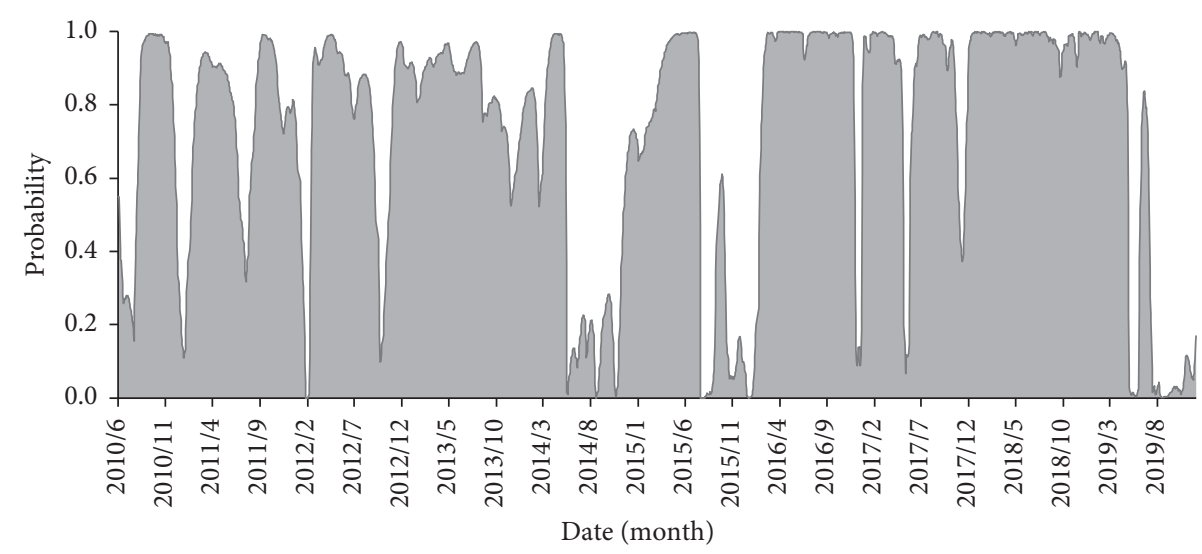

FIGURE 2: Smoothed probabilities of the first regime (low-vol regime).

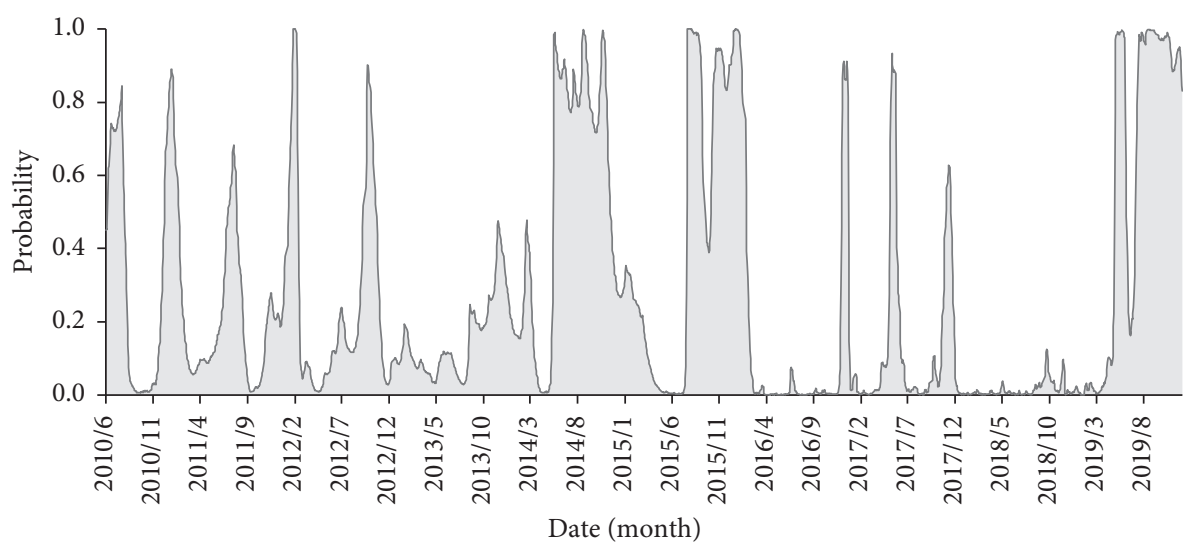

FIGURE 3: Smoothed probabilities of the second regime (high-vol regime).

TABLE 4: Accuracy of VaR predictions. The table reports the actual over expected exceedance ratio (AE) and the statistic and probabilities of the conditional coverage (CC) test and the dynamic quantile (DQ) test for the one-day ahead $1 \%$ VaR.

\begin{tabular}{|c|c|c|c|c|c|c|c|c|c|}
\hline & \multicolumn{3}{|c|}{ CC test } & \multicolumn{3}{|c|}{ DQ test } & \multicolumn{3}{|c|}{$\mathrm{AE}$} \\
\hline & RUSD & $R J P Y$ & RHKD & RUSD & $R J P Y$ & RHKD & RUSD & $R J P Y$ & RHKD \\
\hline \multicolumn{10}{|l|}{ Single regime } \\
\hline GARCH-t & $2.943(0.230)$ & $4.817(0.900)$ & $0.336(0.845)$ & $13.597(0.059)$ & $4.033(0.776)$ & $3.122(0.873)$ & 1.8 & 0.2 & 1.2 \\
\hline GJR-GARCH-t & $0.918(0.632)$ & $4.817(0.090)$ & $0.336(0.845)$ & $8.8980 .260)$ & $3.914(0.790)$ & $9.099(0.246)$ & 1.4 & 0.2 & 1.2 \\
\hline \multicolumn{10}{|l|}{ Two regimes } \\
\hline GARCH-t & $1.799(\mathbf{0 . 4 0 7 )}$ & $4.817(\mathbf{0 . 9 0 0 )}$ & $0.101(\mathbf{0 . 9 5 1 )}$ & $10.043(\mathbf{0 . 1 8 6})$ & $3.485(\mathbf{0 . 8 3 7})$ & $0.788(\mathbf{0 . 9 9 8 )}$ & 1.6 & 0.2 & 1 \\
\hline GJR-GARCH-t & $0.918(\mathbf{0 . 6 3 2 )}$ & $2.369(\mathbf{0 . 3 0 6})$ & $0.336(\mathbf{0 . 8 4 5 )}$ & $3.347(\mathbf{0 . 8 5 1})$ & $2.033(\mathbf{0 . 9 5 8 )}$ & $0.699(\mathbf{0 . 9 9 8 )}$ & 1.4 & 0.4 & 1.2 \\
\hline
\end{tabular}

Note. Numbers in brackets are $p$ values and in bold are highlighted the Markov two-regime GARCH models that outperform their single-regime counterparts.

and the two-regime MSGARCH models. The dynamic VaR value fitted by the GJR-MSGARCH-t model can cover the actual exchange rate loss more effectively, which is also consistent with the conclusion in Table 4. Besides, there is rarely an overestimation of $\mathrm{VaR}$ forecasts, while the singleregime GARCH-t model has an obvious overestimation of $\mathrm{VaR}$ forecasts. In summary, the single-regime GARCH models may underestimate or overestimate the risk of the RMB exchange rate, while the MSGARCH model can predict the VaR risk of RMB exchange rate more accurately.
Considering the domestic and international environment and specific economic events, a coordinated international environment and a stable domestic economic situation are the external conditions and internal driving forces for the stable operation of the RMB exchange rate. Although China's domestic economic imbalance has been improved since 2018, domestic demand has been hindered to some extent by supply-side structural adjustment, slowing down of the real estate market, and structural deleveraging policies. 


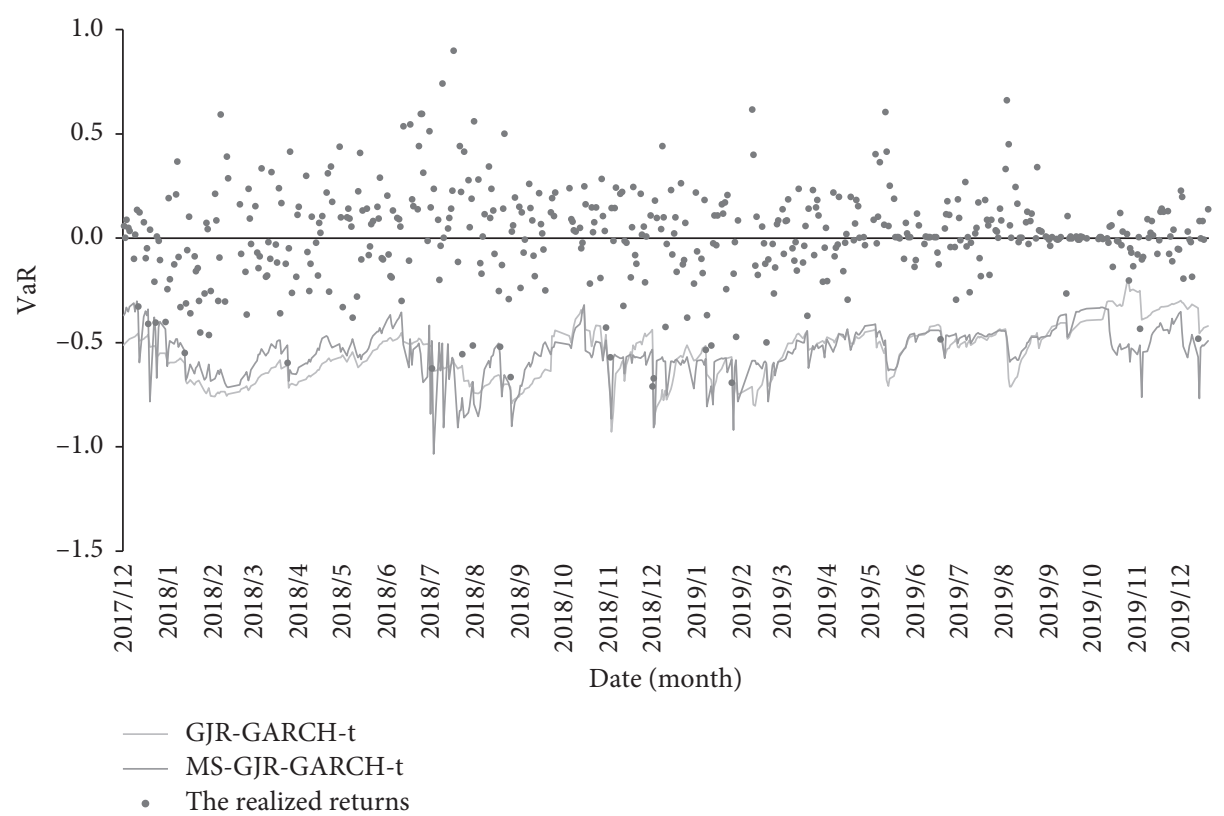

FIGURE 4: One-day ahead VaR forecasts at the $1 \%$ risk level provided by the single-regime and two-regime specifications together with the realized returns.

In contrast, the steady expansion of the US domestic economy has led to the divergence of economic fundamentals between the two countries, leading to high-frequency volatility in the RMB exchange rate. Particularly, since the Sino-US trade war broke out, the volatility of the RMB exchange rate has been particularly severe. Market traders and international investors have panic psychology about the uncertainty of the relationship between the two countries and future development. Although the People's Bank of China has used countercyclical factors to alleviate herd behavior, the RMB exchange rate risk is still at a high level during this period, especially during the whole sample period from the second half of 2018 to the first half of 2019. In the second half of 2019, the trade disputes between China and the United States made some progress, and the VaR forecasts (see Figure 4) showed that the RMB exchange rate risk gradually eased.

\section{Conclusion}

This paper uses GARCH $(1,1)$ models and GJR-GARCH (1, 1) models, considering the Normal distribution, Student- $t$ distribution, and the skewed Student- $t$ distribution. The data is from the daily exchange rate data of the Chinese Yuan (CNY) versus the US dollar (USD), the Japanese Yen (JPY), and Hong Kong dollar (HKD) from June 21, 2010, to December 23, 2019. According to the DIC in the Bayesian estimation method, the fitting effect of single-regime and two-regime MSGARCH models is compared through the Markov Chain Monte Carlo (MCMC) method. And the tworegime MSGARCH model with the best fitting effect is selected to analyze the volatility characteristics of the RMB exchange rate. We also test the performance of the different kinds of model specifications and focus on the one-day ahead VaR forecasts at the 1\% risk level. The following main conclusions are obtained.
Firstly, Markov-switching two-regime GARCH model performs better than single-regime counterparts in fitting the volatility of the RMB exchange rate. The DIC obtained from the Bayesian estimation method shows that the MSGARCH models are better than the single-regime GARCH model in fitting quality and capturing model complexity. For all conditional distribution specifications, the MSGARCH models under the Student- $t$ distribution and the skewed Student- $t$ distribution have a better fitting effect.

Secondly, the volatility of the RMB exchange rate presents a double asymmetric effect. By using the GJRMSGARCH-t model to study the volatility characteristics of the exchange rate versus the US dollar, the Japanese Yen, and Hong Kong dollar, it is concluded that all the exchange rates exhibit regime-switching behavior. The asymmetric effect of $\mathrm{USD} / \mathrm{CNY}$ and $\mathrm{HKD} / \mathrm{CNY}$ is weaker in the stable volatility and more obvious in the turbulent volatility. This is mainly because the Hong Kong Monetary Authority implements a linked exchange rate system linked to the US dollar, so the exchange rates, namely, USD/CNY and HKD/CNY, have similar volatility characteristics. However, the exchange rate of JPY/CNY shows a significant asymmetric effect under both volatility conditions.

Thirdly, the volatility of the RMB exchange rate has obvious characteristics of regime-switching, and the volatility degree of the RMB exchange rate has increased significantly after the exchange rate reform in 2015. Judging from the estimation results of MSGARCH models, the volatilities of all the exchange rates are more likely to be in the same regime. Due to the exchange rate reform in 2015, the entry of RMB into SDR in 2016, and Sino-US trade friction, the exchange rate USD/CNY fluctuated violently for a longer period during the sample period from June 2010 to December 2019. Before the exchange rate reform in 2015, the 
daily exchange rate USD/CNY was in a low-frequency volatility mode for a longer period, and the probabilities of the exchange rates in a turbulent volatility regime were relatively low. The main reasons were the low degree of marketization of RMB exchange rates before the exchange rate reform and the strict exchange rate control by the State Administration of Foreign Exchange. After the exchange rate reform, the degree of RMB exchange rate marketization has gradually increased, the conditional volatility of the exchange rate has increased significantly, and the exchange rate has entered a stage with high probabilities of violent volatility. This also reflects the uncertainty of the RMB exchange rate management system after the exchange rate reform. In addition, the uncertainty of the Sino-US trade war has a significant impact on the RMB exchange rate.

Fourthly, in terms of the accuracy of dynamic VaR risk prediction, Markov-switching two-regime GARCH models outperform the single-regime counterparts. Interestingly, this conclusion is different from previous research (Zhang et al.) and provides a new theoretical basis for risk prediction. The performance of the VaR forecast is tested based on different kinds of MSGARCH models. Model parameters are updated every 10th observation to improve prediction accuracy. According to AE values, the CC test $p$ values, and DQ test $p$ values, we can conclude that tworegime MSGARCH models perform better, showing that two-regime MSGARCH models can more accurately capture the volatility characteristics of the RMB exchange rate. Further, the GJR-GARCH-t models have the highest accuracy in dynamic VaR prediction. In particular, the escalating trade friction between China and the United States has obviously aggravated the volatility of the RMB exchange rates, significantly increasing the risk of RMB exchange rates.

\section{Data Availability}

The data in this article are available from the State Administration of Foreign Exchange.

\section{Conflicts of Interest}

The authors declare that there are no conflicts of interest regarding the publication of this paper.

\section{Acknowledgments}

The work was supported by the Project of Basic Scientific Research Business Expenses of Central Universities (Grant no. 2232020B-02).

\section{Supplementary Materials}

The raw data of the RMB exchange rate price in the empirical part of this paper. (Supplementary Materials)

\section{References}

[1] R. Engle, "Dynamic conditional correlation," Journal of Business \& Economic Statistics, vol. 20, no. 3, pp. 339-350, 2002.

[2] L.-T. Zhao, K. Liu, X.-L. Duan, and M.-F. Li, "Oil price risk evaluation using a novel hybrid model based on time-varying long memory," Energy Economics, vol. 81, pp. 70-78, 2019.

[3] X.-L. Gong, X.-H. Liu, and X. Xiong, "Measuring tail risk with GAS time varying copula, fat tailed GARCH model and hedging for crude oil futures," Pacific-Basin Finance Journal, vol. 55, pp. 95-109, 2019.

[4] X. Pan, "Is there asymmetric "Leverage effect"in exchange rate?-a GARCH-model-based study on the volatility," Contemporary Economy \& Management, vol. 39, no. 1, pp. 81-88, 2017.

[5] Q. He, "Research on exchange rate marketization reform and exchange rate volatility under the new normal state," Studies of International Finance, vol. 3, pp. 67-76, 2017.

[6] S. Sun and W. Sun, "Research on the fluctuation law of RMB exchange rate after joining SDR," On Economic Problems, vol. 2, pp. 42-47, 2019.

[7] J. D. Hamilton, "A new approach to the economic analysis of nonstationary time series and the business cycle," Econometrica, vol. 57, no. 2, pp. 357-384, 1989.

[8] R. Vigfusson, "Switching between chartists and fundamentalists: a Markov regime-switching approach," International Journal of Finance \& Economics, vol. 2, no. 4, pp. 291-305, 1997.

[9] D. Ardia, K. Bluteau, K. Boudt, and L. Catania, "Forecasting risk with Markov-switching GARCH models:A large-scale performance study," International Journal of Forecasting, vol. 34, no. 4, pp. 733-747, 2018.

[10] Y.-J. Zhang and J.-L. Wang, "Do high-frequency stock market data help forecast crude oil prices? Evidence from the MIDAS models," Energy Economics, vol. 78, pp. 192-201, 2019.

[11] Y.-J. Zhang, T. Yao, L.-Y. He, and R. Ripple, "Volatility forecasting of crude oil market: can the regime switching GARCH model beat the single-regime GARCH models?" International Review of Economics \& Finance, vol. 59, pp. 302-317, 2019.

[12] L. Wei, "Institutional investors, sub-owned shares reform and stock returns volatility: MCMC estimation of a MS-GARCH model with student-t error," System Engineering Theory and Practice, vol. 33, no. 3, pp. 545-556, 2013.

[13] J. Yang, L. Yuan, and C. Zhang, "Estimation of VaR based on nonparametric GARCH models with Markov regime switching," Journal of Management Sciences in China, vol. 17, no. 2, pp. 69-80, 2014.

[14] Y. Ji, "China's multiplier-accelerator model analysis based on Markov regime switching theory," Statistics \& Decision, vol. 3, pp. 24-26, 2017.

[15] X. Huang, W. Song, and Z. Liu, "Forecast of exchange rate fluctuation based on Markov state transition GARCH model," Statistics \& Decision, vol. 6, pp. 84-87, 2017.

[16] M. Naeem, A. K. Tiwari, S. Mubashra, and M. Shahbaz, "Modeling volatility of precious metals markets by using regime-switching GARCH models," Resources Policy, vol. 64, Article ID 101497, 2019. 
[17] D. Ardia, K. Bluteau, and M. Rüede, "Regime changes in Bitcoin GARCH volatility dynamics," Finance Research Letters, vol. 29, pp. 266-271, 2019.

[18] S. F. Gray, "Modeling the conditional distribution of interest rates as a regime-switching process," Journal of Financial Economics, vol. 42, no. 1, pp. 27-62, 1996.

[19] M. Haas, "A new approach to markov-switching GARCH models," Journal of Financial Econometrics, vol. 2, no. 4, pp. 493-530, 2004.

[20] P. F. Christoffersen, "Evaluating interval forecasts," International Economic Review, vol. 39, no. 4, pp. 841-862, 1998.

[21] R. F. Engle and S. Manganelli, "CAViaR," Journal of Business \& Economic Statistics, vol. 22, no. 4, pp. 367-381, 2004.

[22] D. J. Spiegelhalter, N. G. Best, B. P. Carlin, and A. van der Linde, "Bayesian measures of model complexity and fit," Journal of the Royal Statistical Society: Series B (Statistical Methodology), vol. 64, no. 4, pp. 583-639, 2002. 